\title{
Knowledge, attitude and experiences of menopause in the postmenopausal women at a tertiary care center: a cross sectional study
}

\author{
Shivraj More*, Sujatha P., Karthiga
}

Department of Obstetrics and Gynecology, Rajiv Gandhi Government Women and Children Hospital, Pondicherry, India

Received: 23 August 2018

Accepted: 27 September 2018

*Correspondence:

Dr. Shivraj More,

E-mail: moreshivraj9@gmail.com

Copyright: (c) the author(s), publisher and licensee Medip Academy. This is an open-access article distributed under the terms of the Creative Commons Attribution Non-Commercial License, which permits unrestricted non-commercial use, distribution, and reproduction in any medium, provided the original work is properly cited.

\begin{abstract}
Background: Menopause is an inevitable milestone in the reproductive life of every woman. The objective is to investigate menopausal knowledge, attitude, symptoms and management among the participants, to identify the differences according to their educational status and to examine correlations of knowledge, attitude and symptoms pertaining to menopause.

Methods: This cross-sectional study was conducted for a period of 10 months in postmenopausal women attending a tertiary care center in Pondicherry, India with a structured questionnaire developed on the basis of the objective of the study.

Results: 330 postmenopausal women were recruited, and all were aware of their postmenopausal status. Mean age at menopause was $45.91 \pm 2.66$ years. $54.5 \%$ were aware about what menopause was while $5.5 \%$ were unaware. $12.1 \%$ had proper knowledge about cause of menopause, whereas 3.6\% said it is due to god's decision / turning point. Most prevalent symptoms were tiredness $(89.6 \%)$ followed by vasomotor symptoms like hot flushes $(88.5 \%)$ and night sweats $(80.3 \%)$. Only $2.1 \%$ had used HRT for menopausal symptoms.

Conclusions: Depth of knowledge is more important when concern is about greater health disrupter which tends to be imperceptible for a long time such as bone health and cardiovascular risk profile. Thus, the government could concentrate on providing health services to women in post reproductive age group also besides women in the reproductive age.
\end{abstract}

Keywords: Attitude, Knowledge, Menopause

\section{INTRODUCTION}

Menopause refers to the last menstrual period. ${ }^{1}$ Menopause is defined as the time of cessation of ovarian function resulting in permanent amenorrhea. A woman is said to have reached menopause when she completes twelve months of amenorrhea in the fourth / fifth decade of life. ${ }^{2}$

130 million Indian women are living beyond menopause since $2015 .{ }^{3}$ With the advent of modern medicine, there is a general increase in life expectancy, thus many women are likely to live for more than two decades beyond menopause, in an oestrogen deficient state. ${ }^{4}$

Some of the menopausal symptoms experienced by these women can be severe enough to affect the normal lifestyle. Hence, menopausal health demands even higher prioritization in Indian scenario.

In India, at present there is no health program that caters to the specific health needs of postmenopausal women. 


\section{METHODS}

Postmenopausal women attending Gynaecology outpatient block and ward in our hospital fulfilling the inclusion criteria were included in the study after the institutional scientific and ethical committee approval. Known case of thyroid and parathyroid disorders, women taking oestrogen and/ or progesterone in the last three months, women with chronic renal disease, known case of genital malignancy were excluded from the study. A detailed history including obstetric, marital, family and past medical and surgical history were obtained after taking a written, informed and valid consent. Patients were interviewed using a pretested, self-designed, semi structured, oral interview-based questionnaire, examined, and investigated during the hospital visit or stay and all details were recorded in a proforma to assess their knowledge, attitude towards menopause. The information regarding the demographic characteristics such as age, educational status, marital status, lifestyle, occupational status as well as clinical symptoms of menopause were collected from each subject. At the end of the study the data was collected, observations tabulated, analyzed with appropriate statistical tests using SSPS software. Outcomes measured were: the knowledge, attitude, symptoms and management among participants and to assess differences in these based on their educational status and correlations of these.

\section{RESULTS}

Mean age distribution of the enrolled subjects was around $54.18 \pm 7.29$ years. Out of 330 patients, $50.6 \%$ belong to rural areas and $49.3 \%$ to urban, $40.6 \%$ studied up to primary school and $31.2 \%$ were illiterate. $42.1 \%$ were unemployed, $29.7 \%$ were unskilled, $14.5 \%$ were semiskilled, $10.9 \%$ were skilled and $2.7 \%$ were clerical/shop owner by occupation. $59.1 \%$ patients belonged to class IV and $0.3 \%$ to class I. $96.4 \%$ were married and staying with husband and $3.6 \%$ were widows at the time of study (Table 1).

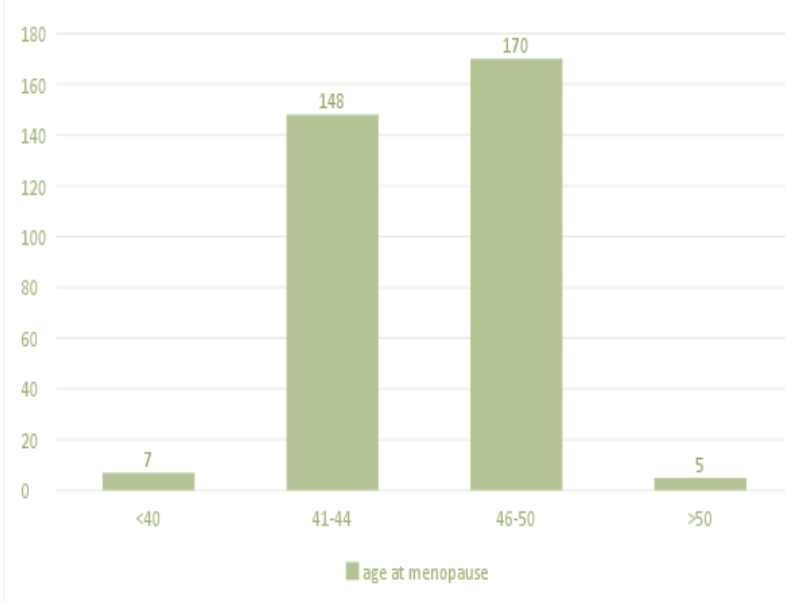

Figure 1: Age at menopause.
Mean age at menopause was $45.91 \pm 2.66$ years. $51.5 \%$ were of age 45-50 years at the time of menopause (Figure 1). $96.9 \%$ had spontaneous menopause and $3.1 \%$ had surgical menopause.

Knowledge among recruited regarding menopause was as follows: $54.5 \%$ related it correctly as stoppage of menses, $40 \%$ opined it as a part of aging and $5.5 \%$ had no idea about what menopause is while. $84.2 \%$ did not have any knowledge about reason behind menopause, $15.8 \%$ had knowledge of why menopause occurs out of which $12.1 \%$ opined it as aging and $3.6 \%$ as turning point /god's decision. Educational status and knowledge about menopause ( $\mathrm{p}$ value $<0.001$ ) were statistically significant. But, this knowledge however was very skimpy and superficial.

Table 1: General characteristics of participants.

\begin{tabular}{|c|c|c|}
\hline General characteristics & $\begin{array}{l}\text { No. of } \\
\text { participants }\end{array}$ & Percentage \\
\hline \multicolumn{3}{|l|}{ Age } \\
\hline $40-49$ & 80 & 24.2 \\
\hline $50-59$ & 181 & 54.8 \\
\hline $60-69$ & 51 & 15.4 \\
\hline$>70$ & 18 & 5.45 \\
\hline \multicolumn{3}{|l|}{ Domicile } \\
\hline Urban & 163 & 49.3 \\
\hline Rural & 167 & 50.6 \\
\hline \multicolumn{3}{|l|}{ Educational status } \\
\hline $\begin{array}{l}\text { Post graduate/ } \\
\text { professional }\end{array}$ & 0 & 0 \\
\hline $\begin{array}{l}\text { Post high school } \\
\text { diploma }\end{array}$ & 5 & 1.5 \\
\hline High school & 20 & 6.06 \\
\hline Middle school & 68 & 20.6 \\
\hline Primary school & 134 & 40.6 \\
\hline Illiterate & 103 & 31.2 \\
\hline \multicolumn{3}{|l|}{ Occupation } \\
\hline Unemployed & 139 & 42.1 \\
\hline Unskilled & 98 & 29.7 \\
\hline Semi-skilled & 48 & 14.5 \\
\hline Skilled & 36 & 10.9 \\
\hline $\begin{array}{l}\text { Clerical/ farmer/ shop } \\
\text { owner }\end{array}$ & 9 & 2.7 \\
\hline \multicolumn{3}{|l|}{ Marital status } \\
\hline Single & 0 & 0 \\
\hline $\begin{array}{l}\text { Married and staying } \\
\text { with husband }\end{array}$ & 318 & 96.4 \\
\hline Divorced & 0 & 0 \\
\hline Widow & 12 & 3.6 \\
\hline \multicolumn{3}{|l|}{ Comorbidities } \\
\hline Nil & 275 & 83.3 \\
\hline Hysterectomised & 8 & 2.4 \\
\hline Other surgeries & 6 & 1.8 \\
\hline Diabetes & 19 & 5.8 \\
\hline Hypertension & 16 & 4.9 \\
\hline $\mathrm{DM}+\mathrm{HTN}$ & 3 & 0.9 \\
\hline Bronchial asthma & 3 & 0.9 \\
\hline
\end{tabular}


None of the subjects were on hormone replacement therapy (HRT) at the time of interview but $2.1 \%$ had used HRT for menopausal symptoms in past and 37 (11.2\%) used other medication such as vitamins $(4.2 \%)$, calcium $(5.5 \%)$, herbs $(0.9 \%)$ and soy $(0.35 \%)$ while $84.5 \%$ were not using any medication/therapy. $8(2.4 \%)$ were using other therapies like acupuncture or yoga for symptoms out of which 5 opined it to be useful but other 3 said it was not helpful. There was statistical significance between their educational status and usage of HRT ( $p$ value $<0.001$ ), while there was no significance with the usage of other medication or therapies.

\section{Experience of menopausal symptoms}

Table 2 shows prevalence of menopausal symptoms. $89.7 \%$ felt tired, $88.5 \%$ had hot flushes and $80.3 \%$-night sweats.

Table 2: Prevalence of menopausal symptoms.

\begin{tabular}{|l|l|}
\hline Symptoms & Prevalence \\
\hline Hot flushes & $88.5 \%$ \\
\hline Night sweats & $80.3 \%$ \\
\hline Difficulty in sleep & $50.6 \%$ \\
\hline Feeling more tired & $89.7 \%$ \\
\hline Concentration difficulty & $71.8 \%$ \\
\hline Poor memory & $32.4 \%$ \\
\hline Feeling more irritable anxious & $60 \%$ \\
\hline Depressed moods & $49.7 \%$ \\
\hline Mood swings & $57.9 \%$ \\
\hline Headaches & $43.6 \%$ \\
\hline Need to urinate often & $43.6 \%$ \\
\hline Burning micturition & $24.2 \%$ \\
\hline Uncontrollable loss of stool/ gas & $6.3 \%$ \\
\hline Vaginal dryness/ itching & $64.5 \%$ \\
\hline Abnormal vaginal discharge & $63.6 \%$ \\
\hline Weight gain & $41.2 \%$ \\
\hline Breast tenderness & $35.4 \%$ \\
\hline Joints pain & $64.5 \%$ \\
\hline
\end{tabular}

$148(44.8 \%)$ were sexually active and $182(55.2 \%)$ were inactive. Out of the 148 sexually active women $63.3 \%$ had loss of interest and $13.5 \%$ had dyspareunia. Urogenital symptoms as described in table 2 .

There was no statistical significant correlation of their knowledge and attitude towards menopause with the experience of symptoms.

\section{Attitude towards menopause and hormone therapy}

$153(46.4 \%)$ had positive attitude towards menopause saying menopause means no more periods and no more worry about contraception and $53.6 \%$ had negative attitude (loss of fertility, femininity and loss of youth) with the following concerns: $12.7 \%$ sleep disturbances, $13.6 \%$ uncontrollable emotions, $17.6 \%$ irritability/ anxiety, $22.1 \%$ weight gain, $27.2 \%$ weakness, $1.8 \%$ incompleteness as a woman, $4.8 \%$ held the view that menopause was end of femininity.

Out of 330, $2(0.6 \%)$ had positive, $2(0.6 \%)$ had negative view towards HRT and $98.8 \%$ had no view. Out of 7 $(2.1 \%)$ who used HRT in the past, $5(1.5 \%)$ felt it is costly and $2(0.6 \%)$ had concerns about side effects.

There was statistical significance between their educational status and attitude about menopause and HRT ( $\mathrm{p}$ value < 0.001 ).

Source of awareness about menopause in the present study was through magazines $(28.7 \%)$, friends $(31.2 \%)$, TV (36.4\%) and healthcare services $(3.7 \%)$. Opinions given regarding services to be provided by healthcare provider were $0.6 \%$ said they wanted more awareness/ community education, $16.1 \%$ needed more attention, $0.1 \%$ said cheaper therapy should be made available, $82.1 \%$ did not have any opinion. Statistical significance between their educational status and opinions given regarding the services to be provided by the healthcare provider $(\mathrm{p}<0.001)$ was seen.

$168(5.1 \%)$ did self-breast examination and $94.8 \%$ did not. $5.4 \%$ were found to be normotensive, $59.1 \%$ prehypertension, $33.6 \%$ stage I hypertension and $1.8 \%$ stage II hypertension. $57.3 \%$ had normal sugars, $40.6 \%$ were pre-diabetic and $2.1 \%$ had diabetic values.

PAP smear was taken for all the 330 participants and 9 $(2.7 \%)$ had unsatisfactory sample, $25.2 \%$ had normal smears, $56.7 \%$ inflammatory smear, and $11.2 \%$ ASCUS/ASC-H/AGC, 1.2\% LSIL (CIN-1), 1.2\% HSIL (CIN$2), 0.6 \%$ HSIL (CIN-3) and $1.2 \%$ had invasive carcinoma in their PAP smear.

Only $2(0.6 \%)$ women did exercise regularly while $99.4 \%$ did not exercise in any manner. $24(7.3 \%)$ felt they were in excellent health whereas $169(51.5 \%)$ felt good, 130 $(39.4 \%)$ felt fair and $6(1.8 \%)$ felt poor about their health.

\section{DISCUSSION}

Most of the women included in the study were either illiterate or studied up to primary school similar to studies by Nisar et al and Akansha et al, whereas in Folsade et al study all subjects were equally distributed. ${ }^{5-7}$ The mean age at menopause in this study was $45.91 \pm 2.66$ years, which corroborated with the findings of other studies (Aarthi $\mathrm{k}$ et al, Akansha $\mathrm{S}$ et al) $(45.8 \pm 4.3,46.24 \pm 3.38$ respectively). ${ }^{6,8}$

Awareness of HRT use was almost negligible as only $2.1 \%$ of the women were aware and had used in the past but discontinued due to fear of drug related side effects. But $37(11.2 \%)$ had used some other medicines like vitamins, calcium, herbs and soy products. Study by Nilanjana das showed that $8 \%$ of study participants had used specific hormonal therapy for menopausal 
symptoms. Usage of calcium, phytoestrogens, soy products and herbal medicines was quite common in postmenopausal women. ${ }^{8-10}$ Hot flushes and night sweats were the most common symptoms, whereas in this study feeling tired was the main complaint. ${ }^{5,6}$ Urogenital and sexual symptoms were very common and were expressed only on questioning.

Vaginal dryness, itching, loss of sexual interest and dyspareunia were predominant complaints and were seen in other studies too. ${ }^{2} 46.4 \%$ had positive attitude towards menopause saying menopause means no more periods and no more worry about contraception and $53.6 \%$ had negative attitude (loss of fertility, femininity and loss of youth). Similarly Das N study showed about $58.5 \%$ considered menopause in a positive attitude. ${ }^{9}$ Fosalade $\mathrm{S}$ et al stated that, $75(21.4 \%)$ had a negative attitude towards it: 52 felt it would make them incomplete as women, the other 23 were concerned that it would be followed by persistent ill health, and others still wanted to have children, while some felt they were too young to undergo menopause. ${ }^{7}$ Eighty-one $(23.0 \%)$ looked forward to a welcome relief from menses. Awareness about menopause in the present study was mainly from magazines $(28.7 \%)$, friends $(31.2 \%)$, TV $(36.4 \%)$ and only $3.1 \%$ from healthcare providers. Aarthi $\mathrm{K}$ et al and Fosalade et al concluded the same. ${ }^{7,8}$

\section{CONCLUSION}

Education is a tool that cannot be ignored, and health education plays an important role in increasing knowledge regarding menopause and hormone replacement therapy among the post-menopausal population. Even meagre level of formal education with low level of social exposure showed significant knowledge enhancement. Hence, improving the educational opportunities is worthwhile. But this should be ensured without upsetting the basic natural acceptance of very tolerant attitude towards menopause which by itself is to be respected. Thoughtless planning or unregulated counselling will dysregulate mental equilibrium hence a tolerant attitude and innate acceptance of slowing down will not complicate their lives. Vasomotor symptoms and urogenital syndrome need to be understood which may be short lived and nuisance provoking. Depth of knowledge is more important when concern is about greater health disrupters which tend to be imperceptible for long time such as bone health and cardiovascular risk profile. Thus, government could concentrate on providing health services to women in post reproductive age group by incorporating national health programs for the health needs of postmenopausal women like screening for early pickup of aging morbidities and malignancies and also enhancing quality of life as in urinary incontinence.

Advice regarding healthy eating and life style changes along with ensuring family support must be provided with the importance of physical exercise must be stressed upon at the community level as a whole. Poor health habits and health concerns need to be addressed and corrected as early as possible with appropriate therapy.

\section{Funding: No funding sources \\ Conflict of interest: None declared}

Ethical approval: The study was approved by the Institutional Ethics Committee

\section{REFERENCES}

1. Dutta R, Dcruze L, Anuradha R, Rao S, Rashmi MR. A population based study on the menopausal symptoms in a rural area of Tamil Nadu, India. J Clin Diagn Res. 2012;6(4):597-601.

2. Satpathy M. A study on age at menopause, menopausal symptoms and problems among urban women from Western Odisha, India. Int J Sci Res Pub. 2016;6(3):422-7.

3. Christian DS, Kathad MM, Bhavsar BS. A clinicoepidemiological study on health problems of postmenopausal women in rural area of Vadodara District, Gujarat. Headache. 2012;110:74-8.

4. Bansal P, Chaudhary A, Soni RK, Kaushal P. Menopausal problems among rural middle-aged women of Punjab. Int $\mathbf{J}$ Res Health Sci. 2013;1(3):103-9.

5. Nisar N, Sohoo NA. Frequency of menopausal symptoms and their impact on the quality of life of women: A hospital based survey. J Pak Med Assoc. 2009;59:752-6.

6. Singh A, Pradhan SK. Menopausal symptoms of postmenopausal women in a rural community of Delhi, India: A cross-sectional study. J Mid-life Health. 2014 Apr;5(2):62-7.

7. Bello FA, Daramola OO. Attitude to the menopause and sex amongst middle-aged women in a family medicine clinic in Ibadan, Nigeria. Obstet Gynecol Int. 2016;2016:1-5.

8. Kaulgekar A. Age of menopause and menopausal symptoms among urban women in Pune, Maharashta. J Obstet Gynaecol India. 2011;61(3):323-6.

9. Alakananda DN, Das BP. Age of menopause and menopausal symptoms among women attending Gauhati Medical College and Hospital, Guwahati, Assam: a cross-sectional study. Sch J App Med Sci (SJAMS). 2015;3(7C):2621-9.

10. Puri S, Bhatia V, Mangat C. Perceptions of menopause and postmenopausal bleeding in women of Chandigarh, India. Internet $\mathrm{J}$ FAM Pract. 2008;6(2):1-6.

Cite this article as: More S, Sujatha $\mathrm{P}$, Karthiga. Knowledge, attitude and experiences of menopause in the postmenopausal women at a tertiary care center: a cross sectional study. Int J Reprod Contracept Obstet Gynecol 2018;7:4758-61. 